\title{
LEVANTAMENTO DOS TRANSFORMADORES ELÉTRICOS POTENCIALMENTE CONTAMINADOS POR BIFENILAS POLICLORADAS EM JOINVILLE/SC
}

\section{USE OF ELECTRICAL TRANSFORMERS POTENTIALLY CONTAMINATED WITH POLYCHLORINATED BIPHENYLS IN JOINVILLE/SC}

\author{
Ana Lúcia Berretta Hurtado ${ }^{1}$; Alexsander S. B. Magalhães ${ }^{2}$; Carlos Alberto Klimeck Gouvêa ${ }^{3}$; \\ André Hideto Futami ${ }^{4}$ \\ ${ }^{1}$ Sociedade Educacional de Santa Catarina - SOCIESC - Joinville - Brasil \\ ana.hurtado@sociesc.org.br \\ ${ }^{2}$ Sociedade Educacional de Santa Catarina - SOCIESC - Joinville - Brasil \\ contato@alexmagalhaes.com \\ ${ }^{3}$ Sociedade Educacional de Santa Catarina - SOCIESC - Joinville - Brasil \\ gouvea@sociesc.org.br \\ ${ }^{4}$ Sociedade Educacional de Santa Catarina - SOCIESC - Joinville - Brasil \\ andre.futami@sociesc.org.br
}

\begin{abstract}
Resumo
As bifenilas policloradas (PCBs) são substâncias tóxicas persistentes altamente nocivas aos mamíferos e estão presentes em óleos sintéticos industriais como o Ascarel ${ }^{\circledR}$. Mesmo com sua produção vetada por lei, dispositivos elétricos, especificamente alguns transformadores, ainda podem estar contaminados por este composto, o qual pode causar contaminações severas ao ambiente quando descartado de forma incorreta. Esta pesquisa tem por objetivo principal estimar a quantidade de óleo possivelmente contaminado por bifenilas policloradas presentes em transformadores elétricos na cidade de Joinville/SC. Valendo-se de um mecanismo de pesquisa desenvolvido especificamente para este fim, baseou-se em estratégias já utilizadas por organizações internacionais do meio ambiente, sem a necessidade da coleta de amostras para análises químicas, em uma tentativa de contribuir para o levantamento da presença de tais substâncias nos transformadores. Ao final desta pesquisa foi possível constatar que, mesmo após quatro décadas da proibição da sua fabricação, ainda é possível encontrar equipamentos contaminados por PCBs, mostrando-se a relevância de tal inventário.
\end{abstract}

Palavras-chave: transformadores elétricos; bifenilas policloradas; óleo Ascarel ${ }^{\circledR}$; substâncias tóxicas persistentes.

\section{Introdução}

Bifenilas policloradas (PCBs) são compostos organoclorados sintetizados para fins industriais, os quais foram utilizados amplamente na área elétrica até os anos 80. Inicialmente produzido em escala industrial nos Estados Unidos e Alemanha, vários congêneres das PCBs foram 
produzidos em outros países, tais como França, Japão e Itália (PENTEADO e VAZ, 2001). No Brasil, a existência do óleo Ascarel ${ }^{\circledR}$, nome comercial do produto que contém aproximadamente $75 \%$ de Aroclor 1254 e $25 \%$ de triclorobenzeno (ANTONELLO et al, 2005), resulta das importações vindas dos Estados Unidos e da Alemanha.

O óleo Ascarel ${ }^{\circledR}$ teve sua fabricação proibida em todo o mundo, mas estima-se que entre 12,9 e $16,5 \%$ da produção original de PCBs ainda permaneça em uso dentro de sistemas fechados de ciclo de vida mais longo (BREIVIK et al, 2007). Os mesmos autores estimam que aproximadamente 1,3 milhões de toneladas de PCBs tenham sido produzidos entre 1930 e 1993 , quando cessou a produção mundial do óleo.

Segundo o Relatório da Organização Mundial da Saúde de 1987, as PCBs estão incluídas no Grupo 2A como prováveis cancerígenos humanos. Por possuírem alta estabilidade química e térmica, essas substâncias são persistentes no ambiente, insolúveis em água, porém extremamente solúveis em óleos vegetais, gorduras animais e em solventes orgânicos (BORJA et al, 2005). Devido a essas características e ao seu uso indiscriminado, as PCBs acumularam-se no meio ambiente (GARRIDO et al, 1992; PLATONOW et al, 1971), sendo que muitos estudos nacionais reportam a presença dessas substâncias em tecidos de animais (LEONEL et al, 2010) e em alimentos processados (BOGUSZ JUNIOR et al, 2004; SANTOS et al, 2006). O problema torna-se maior na medida em que não há uma fiscalização adequada sobre a destinação deste óleo e nem em relação aos resíduos de equipamentos contaminados e as técnicas mais viáveis para sua reciclagem, uma vez que são poucas as empresas habilitadas no Brasil para esse tipo de finalidade.

No Brasil, o uso dessas substâncias foi proibido por meio da Portaria Interministerial (MIC/MI/MME) $n^{\circ}$ 19/81, entretanto a mesma permite que os transformadores elétricos que já possuem o óleo continuem a usá-lo até que haja a necessidade de esvaziar seu reservatório, e só então seja preenchido com outro óleo que não o Ascarel. Dessa forma, apesar da proibição de sua sintetização e utilização em quaisquer tipos de equipamentos, a sua liberação para o ambiente continua, tanto na forma de equipamentos de vida útil mais longa, como na forma de resíduos armazenados. Com a inclusão das PCBs em 2004 pela Convenção de Estocolmo como uma das 12 substâncias químicas objetos de banimento, o Brasil ratificou a Convenção por meio do Decreto no. 5.472, de junho de 2005 assumindo o compromisso internacional de retirar as PCBs de uso até 2025 e, até 2028, baní-lo completamente (MMA, 2012).

Uma das primeiras atividades a serem desenvolvidas em um plano de ações segundo Rae (2001) é o desenvolvimento de um inventário com a identificação dos equipamentos contendo PCBs e a identificação dos locais contaminados por essas substâncias. De modo a atender as exigências da Convenção de Estocolmo, o governo brasileiro deu início à preparação de um inventário nacional com a finalidade de levantar a existência de equipamentos e resíduos 
contaminados por PCBs e proceder ao acompanhamento do ciclo de vida daqueles equipamentos ainda em uso até a sua disposição final (MMA, 2012). Esse procedimento será viabilizado pelo Ministério do Meio Ambiente via Registro de Emissão e Transferência de Poluentes (RETP) obtido no Cadastro Técnico Federal do IBAMA.

Assim sendo, é de extrema importância um levantamento da real situação de transformadores à base de Ascarel $^{\circledR}$ ainda em uso de forma a contribuir para a sua inativação e para o gerenciamento de um descarte correto, evitando maiores contaminações e possíveis acidentes irreversíveis. Neste contexto, este artigo tem por objetivo estimar a quantidade de óleo presente em transformadores elétricos na cidade de Joinville, mostrar qual o risco potencial de contaminação do óleo atualmente utilizado e dos demais equipamentos locais através da diluição do Ascarel ${ }^{\circledR}$, assinalando o grau de preocupação e conhecimento dos envolvidos sobre o assunto, contribuindo para o mapeamento dessas substâncias tóxicas persistentes.

\section{Histórico das bifenilas policloradas}

As bifenilas policloradas foram sintetizadas pela primeira vez por volta de 1881 por Schmidt e Schulz, sendo inicialmente produzidas em escala industrial em 1929 (TANABE, 1988), para aplicações como componentes dielétricos de capacitores eletrolíticos e óleo de transformadores elétricos, como componentes de bombas de vácuo, turbinas de transmissão de gás, fluidos hidráulicos, resinas plastificantes, lubrificantes, óleos de imersão, misturas de pesticidas e papel carbono (PENTEADO et al, 2001). Sua produção ocorreu entre 1920 e 1970, sendo os países industrializados Áustria, China, antiga Tchecoslováquia, França, Alemanha, Itália, Japão, Rússia, Espanha, Reino Unido e Estados Unidos os principais fabricantes (UNEP, 2003). Durante décadas características como alta estabilidade e baixa inflamabilidade e condutividade consagraram as PCBs como o isolante dielétrico líquido mais usado em transformadores e outros equipamentos elétricos (UNEP, 2002).

Dentro dos transformadores elétricos o óleo tem basicamente duas funções: resfriar o núcleo do transformador e criar isolamento elétrico, ou efeito dielétrico através de imersão. Portanto, o setor elétrico é uma fonte ativa de PCB para o ambiente, devido à estocagem primária deste passivo ambiental. Segundo as normas NBR 8371/94 e 13882/97, para o setor de transmissão de energia elétrica são considerados equipamentos elétricos isentos de PCBs aqueles cujo óleo mineral isolante contenha teores inferiores a 3,0 ug/mL, equipamentos não contaminados aqueles com valores inferiores a $50 \mathrm{ug} / \mathrm{mL}$ e contaminados aqueles com valores entre 50 e $500 \mathrm{ug} / \mathrm{mL}$.

Apesar da homologação da Portaria interministerial (MIC/MI/MME) n 19 de 29 de janeiro de 1981, a qual proibiu a instalação de qualquer equipamento que contenha bifenilas policloradas (PCBs) e sua fabricação em território nacional, o uso e a comercialização de PCB puro ou em 
mistura, em qualquer concentração ou estado físico, conforme prazos estabelecidos na própria norma, não decreta o descarte imediato do produto, como se pode observar no item III da mesma Portaria $n^{\circ} 19 / 81$ :

Os equipamentos de sistema elétrico, em operação, que usam bifenil policlorados - PCBs, como fluido dielétrico, poderão continuar com este dielétrico, até que seja necessário o seu esvaziamento, após o que somente poderão ser preenchidos com outro que não contenha PCBs.

Desta forma, mesmo a Portaria Federal proibindo a instalação de novos transformadores com este produto, os equipamentos antigos ainda continuam em uso.

Alguns trabalhos têm levantado a problemática da utilização desses transformadores antigos, relacionando a sua substituição à dificuldade no seu descarte, seja devido ao elevado valor ou às poucas empresas especializadas nesse serviço (Almeida et al, 2007; Leonel et al, 2010; Ricciardi et al, 2008). Para o descarte de resíduos contaminados com Ascarel ${ }^{\circledR}$, a NBR 10004 o classifica como resíduo de Classe I. No Brasil, apenas algumas empresas ambientais fornecem serviços de gerenciamento adequado da destinação final dos transformadores contaminados por essa substância. A Bayer, no Rio de Janeiro e a Cetrel, no Pólo de Camaçari, na Bahia, incineram o óleo e os sólidos contaminados. A Cinal, em Alagoas, queima o líquido isolante, e a WPA, com o escritório em São Paulo e fábrica no Paraná, faz apenas a descontaminação de peças sólidas. A Tecori, em Pindamonhangaba, São Paulo, faz a descontaminação e a reciclagem do metal já descontaminado. Valente (2003) citou estimativas de que no Brasil há cerca de 200 mil toneladas de resíduos de Ascarel, sendo que apenas 1.500 a 2.000 toneladas, ou cerca de 1\%, são tratadas por ano. $\mathrm{O}$ autor salienta que não há análise ou controle da qualidade do óleo processado pelas empresas regeneradoras de óleo isolante de transformadores, o que leva à contaminação nos próprios regeneradores, reintroduzindo traços do óleo Ascarel ${ }^{\circledR}$ em todos os equipamentos. Entretanto, essa preocupação não se concentra somente no Brasil. Uma pesquisa realizada pela UNEP (2004) em 42 empresas espalhadas por vários continentes, mostra que as principais preocupações relacionadas ao gerenciamento dos resíduos de PCBs envolvem treinamento inadequado e falta de consciência sobre os riscos de exposição dos trabalhadores às PCBs em países em desenvolvimento, além das lacunas existentes na legislação sobre uso, gerenciamento e descarte adequado dos óleos e resíduos contaminados por PCBs.

O descarte clandestino, o manuseio inadequado deste óleo ou até o desconhecimento do problema têm suas conseqüências evidenciadas em alguns trabalhos dos últimos anos onde foram mapeadas a presença destes compostos em tecidos de mamíferos marinhos (LEONEL et al, 2010) e alimentos processados (BOGUSZ JUNIOR et al, 2004; SANTOS et al, 2006). A seguir são apresentadas pesquisas relacionadas com a detecção dos efeitos dessas substâncias quando ocorre 
exposição dos seres vivos em vários níveis de contaminação do ambiente, expondo-se a sua periculosidade e evidenciando-se a necessidade do gerenciamento dessa substância.

\section{Efeitos das PCBs na saúde e no ambiente}

Nos animais, a contaminação ocorre principalmente através da cadeia alimentar e a velocidade com que as PCBs são absorvidas ou eliminadas de um animal em geral depende da quantidade de átomos de cloro presentes nas moléculas congêneres de PCB bem como de seu comportamento ou das mudanças climáticas de seu habitat natural (PENTEADO e VAZ, 2001).

Nos seres humanos, a contaminação pode ocorrer tanto através da alimentação como da ingestão crônica de partículas suspensas no ar ou ainda através do contato com a pele.

Estudos realizados por Xing et al (2011) em uma área residencial na China, local de reciclagem massiva de transformadores, mostraram níveis extremamente altos de PCBs no ar e na poeira do solo. Segundo esses autores, embora a inalação não tenha sido o principal fator de contaminação para as pessoas, a poluição atmosférica provavelmente teve papel principal na contaminação de pastagens, animais e plantações que por sua vez entraram na dieta dos moradores da região. Já em Hong Kong, um estudo a respeito do risco de câncer de trabalhadores e da população vizinha de locais de reciclagem e incineração de lixo eletrônico mostrou que estas pessoas possuem um elevado risco de câncer devido à exposição às PCBs, sendo que a incineração a céu aberto apenas potencializa este risco (MAN et al, 2011).

A República Tcheca também faz parte dos países cujo nível de PCBs apresenta-se elevado em relação aos outros países no mundo, o que foi revelado por uma pesquisa na qual os autores mostram que a comida de origem animal é a mais importante fonte de PCBs para sua população adulta em geral (C`ERNÁ M. et al, 2008). Outro estudo, também na República Tcheca, mostra que o país possui os mais altos níveis de PCBs da Europa, pelo menos em sua área industrializada, e encontra congêneros do composto até mesmo em amostras de leite materno ( $C^{\vee}$ ERNÁ M et al, 2010). Petrik et al (2006) também pesquisaram a contaminação no leite materno, mostrando que o nível médio de PCBs de suas crianças é mais alto do que o nível de PCBs em adultos de outros países da Europa. De forma semelhante, no Brasil Kowalski et al (2010) apontam uma correlação entre a contaminação de amostras de leite materno e a alta industrialização das cidades. $\mathrm{O}$ estudo não encontrou vestígios de PCBs em Rio Branco/AC, mas foram encontrados níveis da substância em Vitória/ES e Florianópolis/SC, sendo que as amostras que apresentavam o maior nível encontrado foram aquelas da região metropolitana de São Paulo/SP.

As PCBs, assim como outras substâncias tóxicas persistentes, são conhecidas hoje por serem desreguladores endócrinos, principalmente pela mimetização de hormônios verdadeiros, devido a semelhanças entre suas estruturas moleculares, causando diversos problemas hormonais nos seres 
humanos, sendo que essas alterações podem ser permanentes (QUEIROZ e WAISSMANN, 2006; GIBSON e KOIFMAN, 2008).

A difícil expulsão desse composto químico do corpo humano também pode causar doenças em órgãos específicos como rins, fígado e vesícula biliar e em altos níveis de intoxicação, sintomas como acnes, hiperpigmentação e problemas oculares (PENTEADO e VAZ, 2001). Casos de diabetes, principalmente entre mulheres, também foram estatisticamente estudados apresentando uma forte associação entre o nível de contaminação humana por PCB e a doença, em decorrência da produção de PCBs de 1929 até 1971 no Alabama (BARTE et al, 2012).

Pesquisas sobre a exposição de homens em seu próprio ambiente de trabalho às PCBs mostram que este composto pode diminuir significativamente sua fertilidade e afetar os níveis de estrogênio, hormônios androgênicos, tireoidais, pituitários, corticosteróides e outros hormônios. Outros estudos ainda mostram que meninos nascidos de mães que foram expostas às PCBs apresentaram subdesenvolvimento peniano e, em alguns casos, as PCBs mostraram-se extremamente gonadotóxicas causando alterações testiculares (QUEIROZ e WAISSMANN, 2006). No Brasil foram encontradas fortes evidências de uma provável participação do elevado consumo de agrotóxicos organoclorados, assim como as PCBs, na diminuição da taxa de nascimentos de crianças do sexo masculino (GIBSON e KOIFMAN, 2008).

Devido às evidências encontradas da ação das PCBs sobre o organismo humano, necessitase buscar uma forma de evitar que a quantidade dessas substâncias que ainda se encontram em uso possam causar mais danos à saúde humana e do ambiente.

\section{Procedimentos metodológicos}

A pesquisa caracterizou-se por ser exploratória, buscando um levantamento qualitativo e quantitativo da situação dos transformadores possivelmente contaminados por óleo Ascarel na cidade de Joinville.

Como a pesquisa não previu a possibilidade de análises químicas do óleo dos transformadores para a confirmação da contaminação, partiu-se de uma máxima de que sendo uma substância tóxica persistente (STP), uma vez dentro do transformador, o mesmo, dentro de algumas variantes, seria considerado contaminado. Assim, houve a necessidade de se desenvolver uma ferramenta de pesquisa, no caso um questionário a ser preenchido em pesquisa de campo, que utilizou algumas perguntas na forma de check-list, já conhecidas e utilizadas por organizações internacionais do meio ambiente como a United Nations Environment Programme (UNEP).

Para o desenvolvimento deste questionário e um melhor entendimento do processo de regeneração de óleo empregado pela maioria das empresas especializadas da região, foram realizadas algumas visitas na CELESC, a Companhia Elétrica de Santa Catarina, a qual mostrou 
uma das formas corretas de filtragem e análise de óleo, conforme se pode ver no passo a passo rerpesentado na Figura 1.

Figura 1 - Esquema da filtragem do óleo mineral de transformadores elétricos

\section{1 - O óleo é retirado dos transformadores \\ Em média, $70 \%$ do peso total de um transformador elétrico é o peso do óleo.}

Através de pressão hidráulica, o óleo é empurrado por cima do tanque de expansão do transformador e sugado por baixo para dentro de caminhões pipa.

O processo de esvaziamento pode levar até 10 horas para um transformador de 20.000 litros

O transformador sem óleo é mantido pressurizado com ar seco para evitar a entrada de umidade até receber novo óleo.

\section{2-O transporte é feito até a sede da CELESC em Joinville- SC}

Os caminhões pipa trazem o óleo utilizado nos transformadores da CELESC de todo o estado de Santa Catarina e descarregam na SPSL (Supervisão de Subestações e Linhas de Transmissão) em Joinville, onde o óleo é armazenado até o momento do tratamento.

Antes do tratamento há um pré-processo no denominado Tanque de Óleo Velho (TOV), onde o óleo decanta até o processo de regeneração. Este reservatório suporta até $50.000 \mathrm{~L}$.

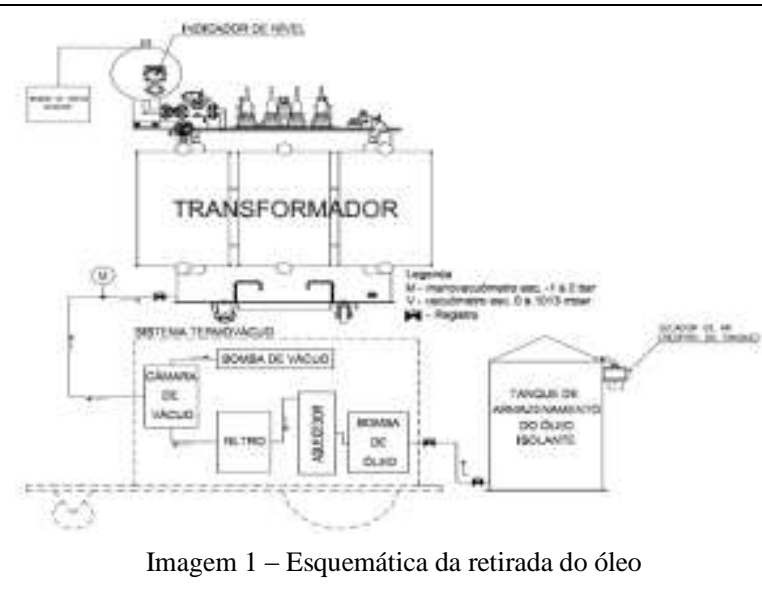

Fonte: Manual de Inst. e Man. para transformadores a óleo WEG

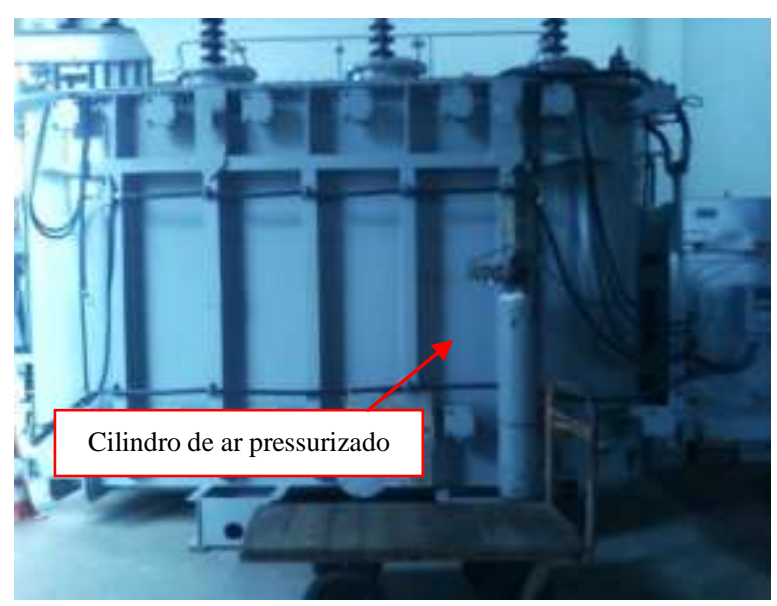

Imagem 2 - Transformador de 15.7001 vazio e pressurizado Fonte: Autoria Própria

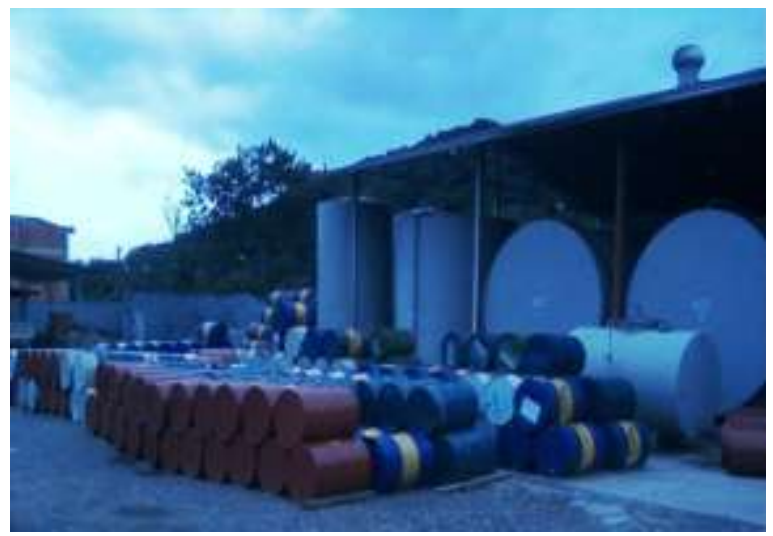

Imagem 3 - Armazenamento do óleo na SPSL Fonte: Autoria Própria 
Parte dos resíduos que contém apenas a bauxita usada aguardam destinação final numa caçamba no pátio da empresa.

\section{3 - O óleo é filtrado na estação de regeneração}

O óleo é bombeado do TOV para dentro de 18 torres de filtragem cheias de bauxita, onde o óleo sujo é filtrado por gravidade e armazenado dentro de tonéis para análise.

O mineral faz a filtragem de partículas em suspensão no óleo e o processo é repetido até que o mesmo esteja livre de impurezas.

Após 3 filtragens, a bauxita das torres é toda substituída e encaminhada para uma empresa especializada fazer o descarte correto.

Depois de constatado pelo laboratório da CELESC que o mesmo está livre de agentes contaminantes, o óleo é aditivado e engalonado ou bombeado para dentro do Tanque de Óleo Regenerado, ou TOR.

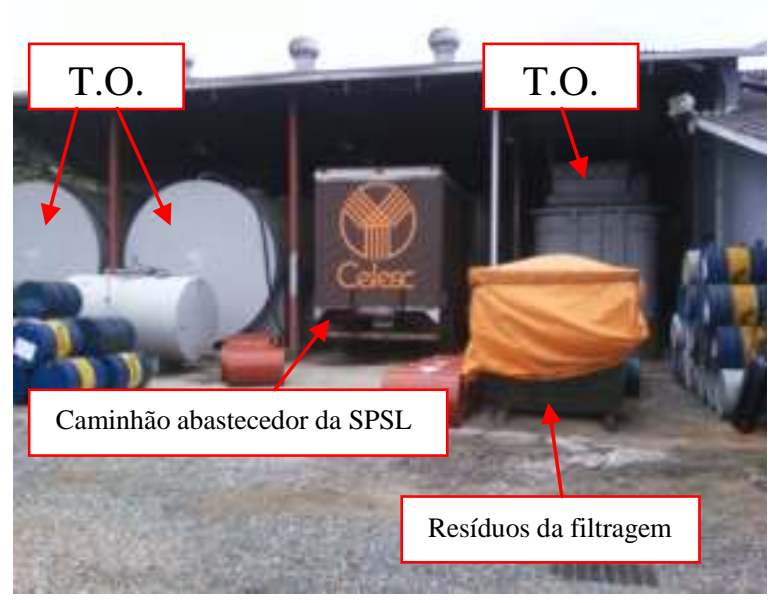

Imagem 4 - Detalhes armazenamento e transporte de óleo Fonte: Autoria Própria

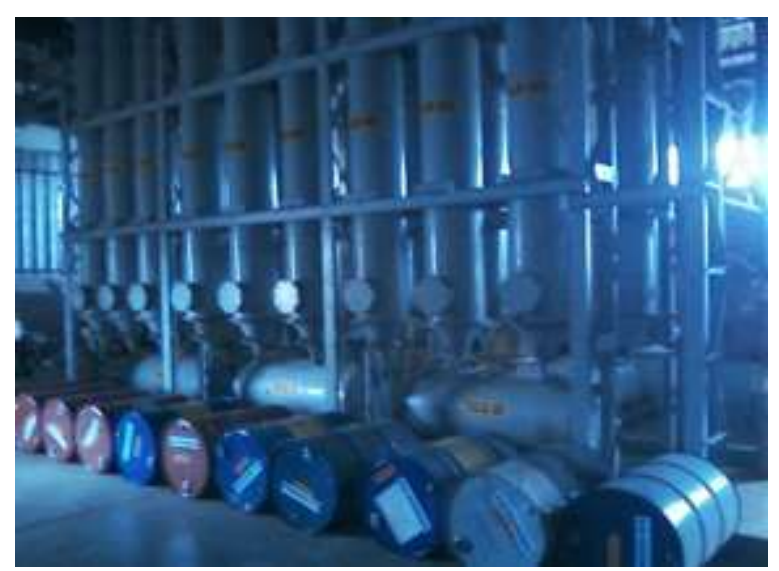

Imagem 5 - Torres de filtragem Fonte: Autoria Própria

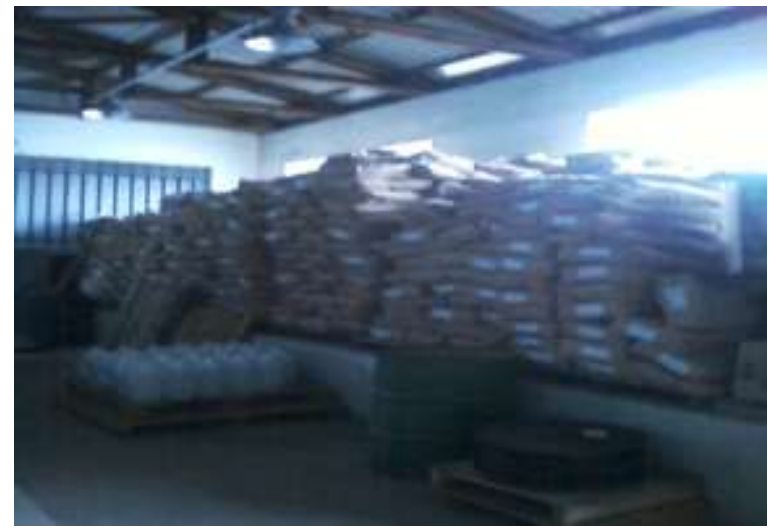

Imagem 6 - Bauxita e aditivos

Fonte: Autoria Própria 
4 - O óleo é transportado de volta ao transformador

O óleo é então transportado por caminhões da SPSL especializados em reabastecimento de transformadores até o local, onde aquecem o óleo a mais de $100^{\circ} \mathrm{C}$ através de resistências elétricas para evaporar gotículas de água acumuladas no óleo e reservam-no numa câmara de vácuo a 0,4 Bar.

Quando o óleo está livre de umidade, é pulverizado sobre as bobinas pré-aquecidas do transformador pressurizado com ar. Este processo é denominado termovácuo e leva no mínimo 24 horas.

Este cuidado impede a formação de bolhas no óleo, o que poderia causar arcos-voltaicos entre as bobinas dos transformadores, destruindo seus enrolamentos e inutilizando-os.

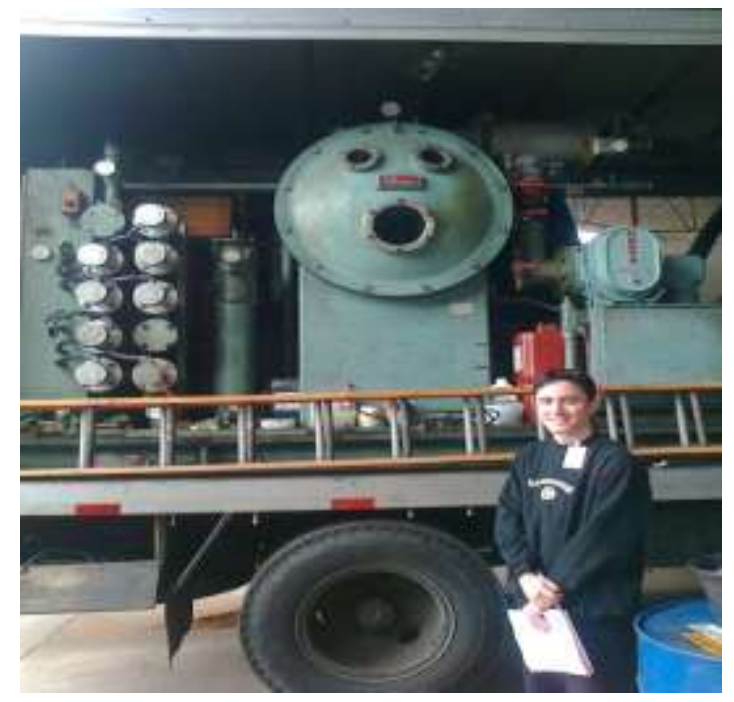

Imagem 7 - Detalhe Caminhão abastecedor da SPSL Fonte:Autoria Própria

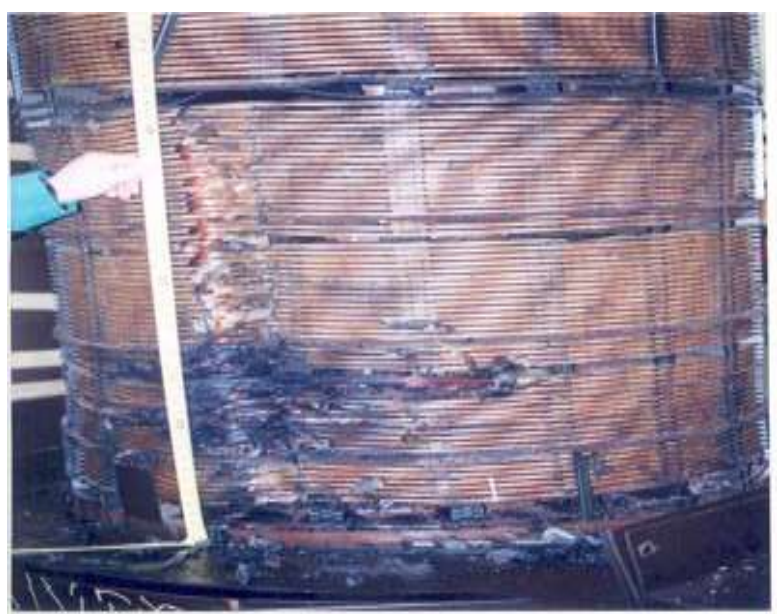

Imagem 8 - Curto circuito em bobinas gerado por arco Fonte: www.edtengineers.com

Fonte: Autoria própria (2012)

Como descrito na Figura 1, após a filtragem algumas amostras são retiradas para análise. A análise química é realizada no laboratório especializado da CELESC em Florianópolis, onde são feitos diversos testes incluindo o teste para detecção de contaminação do óleo por PCBs. Caso seja confirmada esta contaminação, o óleo e os resíduos de sua filtragem são armazenados de forma separada, onde aguardam transporte especializado até seu destino final, sendo este o principal diferencial entre um tratamento correto e um tratamento inadequado.

Após a visita à CELESC e com as informações trocadas com pesquisadores experientes no $2^{\circ}$ CONEPRO-SUL (2012), foi desenvolvido o questionário para ser utilizado no levantamento das informações, o qual procurou classificar a contaminação e o grau de diluição deste óleo contaminado. Como indicadores de contaminação, foram formuladas perguntas buscando a data de fabricação do transformador, o tipo de óleo utilizado e ainda o interesse da empresa proprietária do dispositivo de realizar algum teste de contaminação por PCBs no óleo. Como indicadores de 
diluição, perguntas foram formuladas buscando a periodicidade da manutenção do óleo, terceirização de serviços de manutenção e adequação dos equipamentos utilizados no processo, históricos de manutenção do óleo e do transformador, a prática de substituição, descarte e/ou reabastecimento do óleo, qual o óleo original indicado pelo fabricante, vazamentos acidentais e as providências tomadas ou indicadas pela empresa proprietária do transformador.

Para cada resposta destes dois ramos foram atribuídos pesos, os quais classificam a contaminação do óleo como baixo risco, alto risco e risco iminente de contaminação e, para o grau de diluição, classifica-se como baixo e alto nível de diluição para o meio ou outros equipamentos do gênero. Estes pesos foram definidos na matriz de classificação das respostas do formulário.

Foi definida uma amostra de pesquisa de 8 instituições dentro da cidade de Joinville, sendo estas empresas, hospitais e instituições educacionais, totalizando 42 transformadores elétricos visitados.

\section{Resultados e discussão}

O instrumento principal para o levantamento das informações foi o questionário desenvolvido para a pesquisa em campo, o qual foi elaborado de forma a identificar a utilização de transformadores com óleo Ascarel ${ }^{\circledR}$ propriamente dito ou aqueles que tiveram a diluição do óleo por meio do preenchimento com óleos minerais. A seguir são apresentados os detalhes do referido instrumento de pesquisa com algumas discussões pertinentes:

1. Quantidade de litros de óleo ou peso do transformador: a quantidade de óleo no transformador pode ser medida diretamente em litros, calculada através da massa e de sua densidade tabelada ou ainda assumindo que aproximadamente $70 \%$ do peso do transformador é do óleo. Esta é uma das informações mais importantes do questionário, pois serve como base para o gráfico de contaminação e diluição estimado.

2. Data de fabricação: esta informação é crucial para a estimativa de contaminação, pois se o transformador foi fabricado numa data anterior à lei da proibição do Ascarel ${ }^{\circledR}$, existem grandes chances do mesmo estar contaminado pelo óleo ou até ser portador do mesmo. É importante lembrar que alguns transformadores pesquisados tiveram esta data alterada em sua placa de fabricação de acordo com as regras internas de cada empresa quando, por exemplo, tinham seus conteúdos esvaziados e substituídos por outro óleo, procedimento este inadequado, pois altera o único registro que pode classificar diretamente a vida útil do transformador, sem mencionar o fato de que a simples troca do óleo não elimina totalmente as bifenilas policloradas do reservatório, o que acaba por contaminar o óleo substituto, diluindo a STP no ambiente.

3. Qual o óleo utilizado e quando foi colocado / Existe algum teste de contaminação por PCB's: essas duas perguntas constituem a principal forma de se classificar a contaminação, pois 
informa se o transformador possui ou não Ascarel ${ }^{\circledR}$. Ao final desta pesquisa nenhum transformador foi comunicado como portador de Ascarel, o que já era esperado por parte dos pesquisadores uma vez que desde a sua proibição as pessoas temem alguma fiscalização por parte dos órgãos ambientais.

4. Houve vazamento ou acidente com o transformador / Quais providências foram (seriam) tomadas: embora todas as empresas pesquisadas tenham mostrado conhecimento sobre o assunto, ironicamente algumas admitiram a dificuldade em impedir pequenos gotejamentos de óleo em transformadores antigos que ainda estão em operação, justamente os fabricados anteriormente a 1980. No entanto, nenhum evento além destes gotejamentos foi citado.

5. Periodicidade da manutenção do óleo / A manutenção é terceirizada / Quais os equipamentos utilizados na manutenção / Existe algum histórico desta manutenção* (anexar cópia para análise posterior) / Costuma-se trocar ou completar o óleo / Qual o óleo original (indicado pelo fabricante) / Houve manutenção mecânica ou rebobinamento / Neste caso, o óleo foi mantido ou descartado: essas perguntas pretendem reunir informações gerais sobre estimativas de diluição do óleo dito possivelmente contaminado que foi classificado pelas perguntas anteriores. Quanto à periodicidade de manutenção é fácil notar que quanto maior a periodicidade, maior o nível de diluição deste óleo. Algumas empresas pesquisadas inclusive realizam manutenções preditivas semestrais no óleo de seus transformadores. Quanto à terceirização de serviços e aos equipamentos utilizados, todas as empresas pesquisadas utilizam serviços terceirizados e equipamentos específicos como bombas-filtro, o que no caso de uma filtragem simples em um óleo contaminado, pode causar a contaminação de outros transformadores quando realizadas novas filtragens utilizando o mesmo equipamento, classificando novamente alto nível de diluição no caso de óleo contaminado. Quanto à troca ou preenchimento ocasional do óleo, nenhuma empresa relatou o preenchimento, apenas em alguns casos, relatou-se a substituição do óleo. No quesito manutenção do transformador, não se pode confirmar o tipo nem o número de manutenções nos transformadores mais antigos, pois não houve um histórico detalhado, tampouco a placa do transformador foi mantida inalterada nestes casos. Desta forma, nas empresas pesquisadas alguns transformadores ditos reparados foram considerados como se houvessem sofrido uma única manutenção com exposição do núcleo. Ainda neste contexto, não se pode confirmar se o óleo foi mantido ou trocado.

Ao final da pesquisa, a pesquisa nas 8 instituições de Joinville resultaram no levantamento de 42 transformadores elétricos e aproximadamente 81.000 litros de óleo, dos quais 63\% foram classificados como tendo um baixo risco de contaminação por PBCs, ao passo que $37 \%$ possuem alto risco de contaminação, como mostra a Figura 2. 
Figura 2 - Risco de contaminação do óleo dos transformadores elétricos por PCB

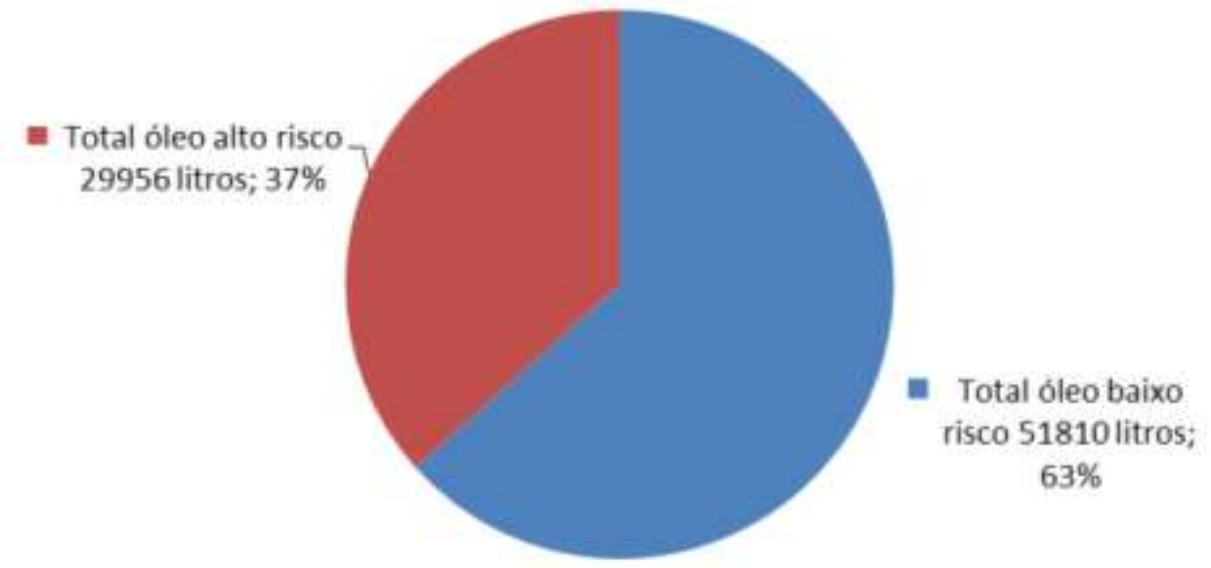

Fonte: Autoria própria (2012)

O nível de diluição deste óleo contaminado é muito alto se levado em consideração o tempo de operação dos transformadores potencialmente contaminados e a recorrência da manutenção dos mesmos, que em alguns casos chega a ser semestral. Desta forma, todo o óleo possivelmente contaminado foi considerado como altamente diluído.

\section{Conclusões}

Ao final desta pesquisa foi possível constatar que mesmo após quatro décadas da proibição da sintetização das PCBs no Brasil, ainda é possível encontrar equipamentos com fortes indícios de contaminação por óleo Ascarel ${ }^{\circledR}$, salientando-se a relevância da fiscalização e manutenção de tal inventário.

É importante ressaltar que sem o auxílio de uma análise química, não foi possível comprovar a contaminação destes fluidos por PCB, assim a pesquisa classificou o risco da contaminação destes isolantes através da data de fabricação, por exemplo, que é um forte indicador de contaminação, pois, transformadores fabricados antes de 1980, mesmo que hoje recondicionados, ou que tiveram seu óleo substituído, ainda podem apresentar traços de PCB.

Neste contexto, embora não tenha sido possível encontrar equipamentos com óleo Ascarel ${ }^{\circledR}$ puro, relatos dos funcionários do setor elétrico e documentos de inventário destas instituições demonstram que as mesmas já possuíram transformadores que utilizavam este óleo e que na data desta pesquisa já haviam sido leiloados ou descartados.

Infelizmente, para tais casos não foi possível comprovar o destino dos mesmos, mas é preciso ressaltar que o crime ambiental não está na emissão do poluente, mas é caracterizado na negligência do emissor quando reporta aos órgãos responsáveis inverdades sobre a quantidade ou destinação deste poluente. 


\begin{abstract}
Polychlorinated biphenyls are highly persistent toxic substances which are harmful to mammals and are present in synthetic oils such as industrial Ascarel ${ }^{\circledR}$. Even with its production prohibited by law, some equipment, specifically transformers may still be contaminated by this substance which if improperly disposed can cause extreme environmental contamination. This paper aimed estimating the amount of oil possibly contaminated by polychlorinated biphenyls present in electrical transformers in Joinville / SC. Making use of a search instrument developed specifically for this purpose, it was based on strategies already used by international environmental organizations, without the need for the collection of samples for chemical analysis, in an attempt to contribute to the mapping of such substances. At the end of this research it was found that, even after four decades of prohibition of manufacturing, it is still possible to find equipment contaminated by Ascarel ${ }^{\circledR}$, showing the relevance of such inventory.
\end{abstract}

Key-words: electric transformers; polychlorinated biphenyls; Ascarel oil ${ }^{\circledR}$; persistent toxic substances.

\title{
Referências
}

ALMEIDA, F.V.; CENTENO, A.J.; BISINOTI, M.C.; JARDIM, W.F. Substâncias tóxicas persistentes (STP) no Brasil. Química Nova, v.30, n.8, p.1976-1985, 2007.

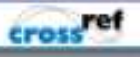

ANTONELlO, I.; HUMERES, E.; SOUZA, I.G.; DEBACHER, N.A.; MARTINS, A.R. Determinação de Ascarel em óleo isolante de transformadores. Química Nova, v.30, n.3, p.709-711, 2007.

cross'

ASSOCIAÇÃO BRASILEIRA DE NORMAS TÉCNICAS. Instrução Normativa $n^{\circ} 001$ de 10/06/83. São Paulo: ABNT, 1994 (NBR 10004).

ASSOCIAÇÃO BRASILEIRA DE NORMAS TÉCNICAS. Ascarel para transformadores e capacitores Características e riscos. São Paulo: ABNT, 1994 (NBR 8371).

ASSOCIAÇÃO BRASILEIRA DE NORMAS TÉCNICAS. Líquidos isolantes elétricos - Determinação do teor de Bifenilas Policloradas. São Paulo: ABNT, (NBR 13882).

BARTE S. M.; FOUSHEE H. R.; PAVUK M.; ROSENBAUM P. F.; SHELTON C.; SILVERSTONE A. E. Polychlorinated biphenyl (PCB) exposure and diabetes: results from the Anniston Community Health Survey. Environmental Health Perspectives, v.120, n.5, p.727, 2012.

\section{cross ref}

BOGUSZ JUNIOR, S.; DOS SANTOS, J.S.; XAVIER, A.A.O.; WEBER, J.; LEÃES, F.L.; COSTABEBER, I. Contaminação por compostos organoclorados em salsichas de hot-dog comercializadas na cidade de Santa Maria (RS), Brasil. Ciência Rural, v.34, n.5 p.1593-1596, 2004.

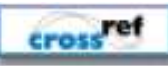

BREIVIK, K.; et al., Towards a global historical emission inventory for selected PCB congeners a mass balance approach: 1. Global production and consumption. The Science of The Total Environment, v. 290, n.1-3, p. 181-198, 2002.

crossef

BORJA, J.; TALEON, D.M.; AURESENIA, J.; GALLARDO, S. Polychlorinated biphenyls and their biodegradation. Process Biochemistry, v.40, p.1999-2014, 2005.

cross ref

C`ERNÁ M.; MALÝ M.; GRABIC R.; BATÁRIOVÁ A.; ŠMÍD J.; BENEŠ B. Serum concentrations of indicator PCB congeners in the Czech adult population. Chemosphere, v.78, p.160-168, 2010. 
C ERNÁ M.; BENCKO V.; BRABEC M.; ŠMÍD J.; KRSKOVA A.; JECH L. Exposure assessment of breast-fed infants in the Czech Republic to indicator PCBs and selected chlorinated pesticides: Area-related differences. Chemosphere, v.72, p.1124-1131, 2008.

GARRIDO, F.M.D.; JODRAL, V.M.L; POZO, L.R. Bifenilos policlorados em leches esterilizadas españolas y estúdio experimental del efecto de la temperatura sobre estos compuestos. ILE - Industrias Lacteas Españolas, v.179, p.3540, 1992.

GIBSON G.; KOIFMAN S. Consumo de agrotóxicos e distribuição temporal da proporção de nascimentos masculinos no Estado do Paraná, Brasil. Rev. Panam. Salud Publica, v. 24, n.4, p.240-7, 2008.

cross ref

KOWALSKI C. H.; COSTA J. G.; GODOY H. T.; AUGUSTO F. Determination of Polychlorinated Biphenyls in Brazilian Breast Milk Samples using Solid-Phase Microextraction and Gas Chromatography-Electron Capture Detection. J. Braz. Chem. Soc., v. 21, n. 3, p.502-509, 2010.

\section{cross}

LEONEL, J.; SERICANO, J.L.; FILLMANN, G.; SECCHI, E.; MONTONE, R.C. Long-term trends of polychlorinated biphenyls and chlorinated pesticides in franciscana dolphin (Pontoporia blainvillei) from southern Brazil. Marine Pollution Bulletin, v.60, p.412-418, 2010.

cross ref

MAN Y. B.; LOPEZ B. N.; WANG H. S.; LEUNG A. O. W.; CHOW K. L.; WONG M. H. Cancer risk assessment of polybrominated diphenyl ethers (PBDEs) and polychlorinated biphenyls (PCBs) in former agricultural soils of Hong Kong. Journal of Hazardous Materials, v.195, p.92- 99, 2011.

\section{cross ref}

MINISTÉRIO DO INTERIOR. Portaria Interministerial (MIC/MI/MME) nº 019, de 29 de janeiro de 1998, que dispõe sobre fabricação e uso de Ascarel.

MINISTÉRIO DO MEIO AMBIENTE. Guia para o inventário nacional de Bifenilas Policloradas (PCB). 2012. 83p.

PETRIK, J.; DROBNA B.; PAVUK M.; JURSA S.; WIMMEROVA S.; CHOVANCOVA J. Serum PCBs and organochlorine pesticides in Slovakia: Age, gender, and residence as determinants of organochlorine concentrations. Chemosphere, v. 65, p. 410-418, 2006.

cross ${ }^{\text {ref }}$

PENTEADO, J.C.P.; VAZ, J. M. O legado das bifenilas policloradas (PCBs). Química Nova, v.24, n.3, p.390-398, 2001.

cross ref

PLATONOW, N.S.; SACHENBECKER, P.W.; FUNNEL, H.S. Residues of polychlorinated biphenyls in cattle. Canadian Veterinary Journal, v.12, p.115-118, 1971.

PORTAL ENERGIA HOJE. Acesso em 10 de julho de 2010. Disponível em http://www.energiahoje.com.

PORTAL DA SECRETARIA DO MEIO AMBIENTE DO ESTADO DE SÃO PAULO. Acesso em 10 de julho de 2010. Disponível em http://www.ambiente.sp.gov.br.

QUEIROZ E. K. R.; WAISSMANN W. Exposição ocupacional e efeitos sobre o sistema reprodutor masculino. Caderno de Saúde Pública, v.22, n.3, p.485-493, 2006.

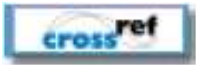

RAE, I. D. Framework for the management of PCBs. Intergovernmental Forum on Chemical Safety. 2001. 16p.

RELATÓRIO DA ORGANIZAÇÃO MUNDIAL DA SAÚDE. Comitê Regional Africano. 37ª Sessão. Bamaco, 1987. 206p. 
RICCIARDI, T.R.; MORAES, M.O. DE; MICHELUTTI, F.L. Avaliação da qualidade da energia elétrica no campus da Unicamp em Barão Geraldo. Revista Ciências do Ambiente On-line, v.4, n.1, p.28-36, 2008.

SANTOS, J.S.; XAVIER, A.A.O.; RIES, E.F.; COSTABEBER, I.; EMANUELLI, T. Assessment of polychlorinated biphenyls (PCBs) in cheese from Rio Grande do Sul, Brazil. Chemosphere, v.65, p.1544-1550, 2006.

cross ref

TANABE, S. PCB problems in the future: foresight from current knowledge. Environmental Pollution, v.50, p.5-28, 1988.

cross ref

UNITED NATIONS ENVIRONMENT PROGRAMME. PCB Transformers and Capacitors: from Management to Reclassification and Disposal. 2002. 71p.

UNITED NATIONS ENVIRONMENT PROGRAMME. Training Manual for the preparation of a national Environmentally Sound Management plan for PCBs and PCB-contaminated equipment in the framework of the implementation of the Basel Convention. 2003.103p.

UNITED NATIONS ENVIRONMENT PROGRAMME. Inventory of World-wide PCB Destruction Capacity. 2004. 78p.

XING G. H.; LIANG Y.; CHEN L. X.; WU S. C.; WONG M. H. Exposure to PCBs, through inhalation, dermal contact and dust ingestion at Taizhou, China - A major site for recycling transformers, Chemosphere, v.83, p. 605-611, 2011.

cross ref

\section{Agradecimentos}

Os autores agradecem ao CNPq pelo auxílio no desenvolvimento desta pesquisa.

\section{Dados dos Autores:}

\section{Nome Completo: Ana Lucia Berretta Hurtado}

Filiação institucional: Instituto Superior Tupy - SOCIESC

Departamento: Pesquisa

Função ou cargo ocupado: Professor Pesquisador

Endereço completo para correspondência (bairro, cidade, estado, país e

CEP): Rua Albano Schmidt, 3333 - Campus Boa Vista - Joinville - SC - Brasil - CEP 89206-301

Telefones para contato: (47) 34610277 (47) 34610256

e-mail: ana.hurtado@sociesc.org.br

\section{Nome Completo: Alexsander Scaratti Botelho de Magalhães}

Filiação institucional: Instituto Superior Tupy - SOCIESC

Departamento: Graduação

Função ou cargo ocupado: Estudante

Endereço completo para correspondência (bairro, cidade, estado, país e 
CEP): Rua Albano Schmidt, 3333 - Campus Boa Vista - Joinville - SC - Brasil - CEP 89206-301 Telefones para contato: (47) 34610277 (47) 34610256

e-mail: contato@alexmagalhaes.com

\section{Nome Completo: Carlos Alberto Klimeck Gouvêa}

Filiação institucional: Instituto Superior Tupy - SOCIESC

Departamento: Pesquisa

Função ou cargo ocupado: Professor Pesquisador

Endereço completo para correspondência (bairro, cidade, estado, país e

CEP): Rua Albano Schmidt, 3333 - Campus Boa Vista - Joinville - SC - Brasil - CEP 89206-301

Telefones para contato: (47) 34610277 (47) 34610256

e-mail: gouvea@sociesc.org.br

\section{Nome Completo: André Hideto Futami}

Filiação institucional: Instituto Superior Tupy - SOCIESC

Departamento: Pesquisa

Função ou cargo ocupado: Professor Pesquisador

Endereço completo para correspondência (bairro, cidade, estado, país e

CEP): Rua Albano Schmidt, 3333 - Campus Boa Vista - Joinville - SC - Brasil - CEP 89206-301

Telefones para contato: (47) 34610277 (47) 34610256

e-mail: andre.futami@sociesc.org.br

Enviado em: 06/12/2012

Aprovado em: $24 / 01 / 2013$ 